\title{
OPTIMALISASI FINANCIAL TEKNOLOGI (FINTECH) TERHADAP PENINGKATAN LITERASI DAN INKLUSI KEUANGAN USAHA MENENGAH PURWOKERTO
}

\author{
Cut Misni Mulasiwi ${ }^{1 *}$, Karina Odia Julialevi ${ }^{2}$ \\ ${ }^{1}$ Jurusan Manajemen, Fakultas Ekonomi dan Bisnis, Universitas Jenderal Soedirman, JI. HR \\ Boenyamin No. 708, Purwokerto 53122, Jawa Tengah, Indonesia \\ ${ }^{2}$ Jurusan Akuntansi, Fakultas Ekonomi dan Bisnis, Universitas Jenderal Soedirman, Jl. HR \\ Boenyamin No. 708, Purwokerto 53122, Jawa Tengah, Indonesia \\ *Email corresponding author: cutmisnimulasiwi@unsoed.ac.id. \\ Diterima 14/01/2020 Direvisi 10/02/2020 Diterbitkan 31/01/2020
}

\begin{abstract}
Abstrak
Tujuan dari penelitian ini adalah untuk menjelaskan pengaruh layanan keuangan berbasis fintech terhadap literasi keuangan dan inklusi keuangan Usaha Menengah di Purwokerto. Untuk menguji model empiris, digunakan alat analisis Structural Equation Modelling (SEM). Alat analisis lain yang digunakan antara lain AMOS 21.0, SPSS 16.0 dan Microsoft Excel 2010. Jumlah sampel dalam penelitian ini adalah 108 pemilik usaha menengah dengan menggunakan sampel jenuh. Hasil dari penelitian ini menunjukkan bahwa layanan keuangan berbasis fintech memiliki pengaruh positif terhadap literasi keuangan dan inklusi keuangan usaha micro di Purwokerto.
\end{abstract}

Kata Kunci: Fintech, Literasi Keuangan, Inklusi Keuangan

\begin{abstract}
The purpose of this study is to explain the effect of fintech-based financial services on financial literacy and financial inclusion on Medium Enterprises in Purwokerto. To test the empirical model, Structural Equation Modeling (SEM) analysis was used. Other analysis tools used included AMOS 21.0, SPSS 16.0 and Microsoft Excel 2010. The number of samples in this study was 108 micro business owners by using saturated sampling method. The results of this study indicate that fintech-based financial services have a positive influence on financial literacy and micro-business financial inclusion in Purwokerto.
\end{abstract}

Keywords: Fintech, Financial Literacy, Financial Inclusion. 


\section{PENDAHULUAN}

Era globalisasi mendorong perkembangan bisnis jasa keuangan untuk terus berkembang di Indonesia seiring dengan makin canggihnya tekonologi. Inovasi baru di bidang finansial terus dikembangkan agar dapat memanjakan pebisnis khususnya pebisnis online dalam bertransaksi. Hadirnya perusahaan Financial Technologi di Indonesia ternyata berkembang cukup pesat. Semakin tingginnya animo masyarakat Indonesia menggunakan layanan ini membuat teknologi tersebut digandrungi oleh para pengguna sehingga dominasi penggunaan fintech semakin tinggi. National Digital Research Centre (NDRC) pada tahun 2017 memaparkan bahwa fintech merujuk pada inovasi dalam bidang jasa finansial atau inovasi finansial yang diberi sentuhan teknologi modern. Tidak berbeda jauh dengan Bank Indonesia (2017) yang mendefinisikan financial technology sebagai hasil gabungan antara teknologi dan jasa keuangan, yang mengubah model bisnis dari konvensional menjadi moderat. Jadi, yang pada awalnya harus melakukan transaksi dengan bertemu langsung atau bertatap muka, kini bisa dilakukan walau dengan jarak jauh dalam hitungan detik saja. Uraian diatas terbukti lewat grafik berikut ini:

\section{Perkembangan pesat fintech di Indonesia, 2019}

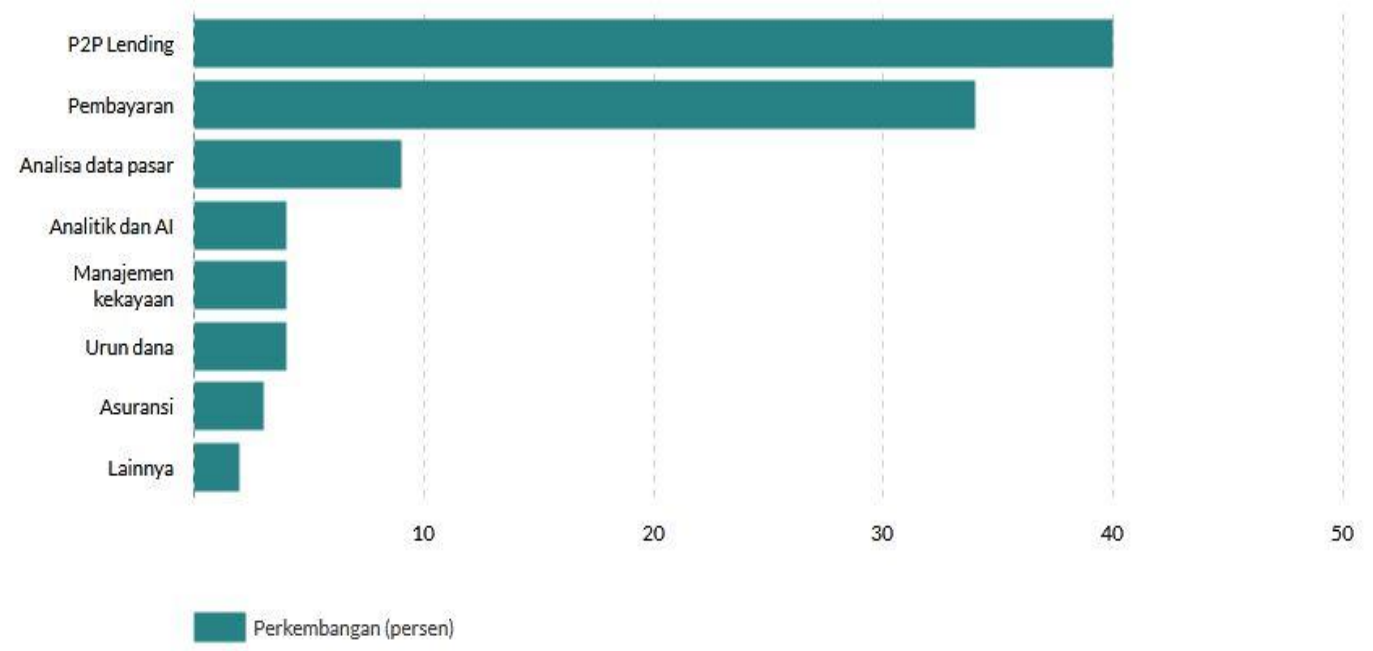

Sumber: Bank Indonesian dan OJK

Gambar 1. Perkembangan pesat fintech di Indonesia, 2019

Ariyanti (2018) memaparkan salah satu poin penting yang tertuang di dalam aturan terbaru POJK No. 13/2018 tentang Inovasi Keuangan Digital (IKD) di Sektor Jasa Keuangan bahwa perusahaan fintech wajib melaksanakan kegiatan yang mampu meningkatkan literasi dan inklusi keuangan kepada masyarakat. Masyarakat disini tentu saja termasuk terhadap pelaku usaha menengah. Seiring perkembangan jaman trend dalam kehidupan silih berganti tidak hanya pada fashion tetapi juga bidang bisnis. Setiap tahunnya bisnis UMKM terus berkembang pesat khususnya e-commerce atau bisnis online. Data Sensus Ekonomi 2016 dari Badan Pusat Statistik menyebutkan bahwa dalam sepuluh tahun terakhir, industri e-commerce di Indonesia tumbuh sekitar 17\% dengan total jumlah usaha mencapai 26,2 juta unit.

Berdasarkan rilis Survei Nasional Literasi dan Inklusi Keuangan dari Otoritas Jasa Keuangan (OJK) 2019, hasil survei pada November 2019 menunjukan masyarakat Indonesia memiliki: indeks literasi keuangan masyarakat perkotaan sebesar $41,41 \%$ dan indeks inklusi keuangan masyarakat perkotaan sebesar $83,60 \%$ sedangkan indeks literasi keuangan masyarakat 
Performance. Volume 27 Nomor 1 Tahun 2020, 12-20

perdesaan sebesar $34,53 \%$ dan indeks inklusi keuangan masyarakat perdesaan sebesar 68,49\%. Sementara secara nasional, hasil Survey Nasional Literasi Keuangan Tahun 2019 menunjukkan indeks literasi keuangan nasional mencapai 38,03\% dan indeks inklusi keuangan nasional 76,19\%. Apabila dibandingkan dengan indeks literasi keuangan dan indeks inklusi keuangan di ASEAN saja, Singapura angkanya sampai 98\%, Malaysia $85 \%$, Thailand $82 \%$ (Setiawan, 2020), maka angka kita masih lebih rendah. Artinya sangat darurat untuk dilakukan akselerasi peningkatan indeks literasi keuangan syariah dan indeks inklusi (Djawahir, 2018).

Usaha Mikro Kecil dan Menengah (UMKM) memiliki peran besar dalam upaya peningkatan pembangunan ekonomi di Indonesia, pertumbuhan ekonomi serta membuka lapangan kerja baru. Saat ini, jumlah UMKM di Indonesia terus meningkat dan berkembang dengan bermacammacam sektor. Dengan peningkatan dan perkembangan dari UMKM diharapkan bisa meningkatkan Produk Domestik Bruto dan menyerap lebih banyak tenaga kerja baru untuk mengurangi pengangguran dan kemiskinan. Karena banyaknya UMKM yang bermunculan membuat persaingan menjadi lebih ketat.

Munculnya inovasi fintech memberikan angin segar untuk pelaku bisnis UMKM. Fintech membantu pelaku bisnis untuk lebih mudah mendapatkan akses terhadap produk keuangan dan meningkatkan literasi keuangan (Sugiarti, 2019). Pelaku bisnis bisa memanfaatkan fintech sebagai jalan untuk pembiayaan perusahaannya. Berdasarkan penelitian tentang peran fintech terhadap UMKM hasil penelitian dari Irmawati et al (2018) menyatakan bahwa kehadiran sejumlah fintech turut memberikan kontribusi dalam pengembangan UMKM. Peran fintech tidak hanya sebatas dalam pembiayaan modal usaha tetapi ada juga yang merambah ke berbagai aspek seperti layanan pembayaran digital juga pengatur keuangan.

Fitriani (2018) menyatakan bahwa fintech telah menyerap banyak perhatian masyarakat karena layanan ini menyediakan berbagai fitur layanan dari fnancial, perbankan, dan asuransi. Maka diperlukan upaya agar masyarakat dalam hal ini khususnya usaha menengah terus melakukan usahanya dengan layanan fintech. Salah satu aspek untuk meningkatkan inklusi keuangan adalah melalui peran fintech (Muzdalifa, 2018). Layanan keuangan melalui fintech dapat berupa pembayaran, investasi, peminjaman uang, transfer, rencana keuangan dan pembanding produk keuangan.

Berdasarkan uraian di atas, peneliti tertarik untuk meneliti mengenai layanan fintech yang saat ini sedang marak digunakan oleh generasi milenial baik dalam lingkup pribadi maupun UMKM. Penelitian yang selama ini di lakukan masih terbatas pada pengaruh fintech terhadap literasi keuangan dan pengaruh fintech terhadap inklusi keuangan. Oleh karena itu peneliti tertarik untuk meneliti pengaruh layanan fintech terhadap literasi keuangan dan inklusi keuangan UMKM. Hal ini dirasa perlu karena kita menyongsong revolusi industri 4.0. Sesuai dengan saran dari penelitian sebelumnya maka dalam penelitian ini akan diteliti apakah layanan keuangan berbasis fintech berpengaruh terhadap literasi keuangan dan inklusi keuangan usaha menengah di Purwokerto. Berdasarkan pada penelitian terdahulu, maka dalam penelitian ini dirumuskan permasalahan apakah layanan keuangan berbasis fintech berpengaruh terhadap literasi keuangan usaha menengah di Purwokerto dan apakah layanan keuangan berbasis fintech berpengaruh terhadap inklusi keuangan usaha menengah di Purwokerto.

Penelitian ini bertujuan untuk mengembangkan penelitian terdahulu mengenai pengaruh layanan keuangan berbasis fintech terhadap literasi keuangan dan inklusi keuangan usaha micro di Purwokerto serta sekaligus ingin mengetahui variabel-variabel yang dapat mempengaruhi tingkat literasi keuangan dan inklusi keuangan usaha micro di Purwokerto. Berdasarkan uraian diatas maka tujuan khusus penelitian ini adalah menganalisis pengaruh layanan keuangan berbasis fintech terhadap literasi keuangan usaha menengah di Purwokerto dan menganalisis pengaruh layanan keuangan berbasis fintech terhadap inklusi keuangan 
Performance. Volume 27 Nomor 1 Tahun 2020, 12-20

usaha menengah di Purwokerto. Melalui penelitian ini diharapkan dapat mengembangkan hasil penelitian mengenai pengaruh fintech terhadap literasi keuangan Sugiarti (2019), Aliyah (2019), dan penelitian (Muzdalifa, 2018), (Ozili, 2018) mengenai pengaruh fintech terhadaap peningkatan inklusi keuangan. Sebagai bahan pertimbangan dan tambahan informasi dalam menyusun strategi peningkatan literasi keuangan dan inklusi keuangan khususnya yang berkaitan dengan pemberian layanan keuangan berbasis fintech agar mampu mendorong tercapainya tujuan Otoritas Jasa Keuangan dalam meningkatkan literasi keuangan dan inklusi keuangan masyarakat Indonesia.

\section{TINJAUAN PUSTAKA DAN PERUMUSAN HIPOTESIS}

\section{Fintech dan Literasi Keuangan}

Fintech terlihat sebagai pasar baru yang memadukan keuangan dan teknologi (Arner, Barberis, \& Buckley, 2015), dan menggantikan struktur keuangan tradisional dengan proses berbasis teknologi baru. (Romanova \& Kudinska, 2016) menyatakan bahwa fintech merupakan salah satu bisnis berbasis software dan teknologi modern yang menyediakan jasa keuangan. Technology Acceptance Model (TAM) merupakan salah satu model yang dibangun untuk menganalisis dan memahami faktor-faktor yang mempengaruhi diterimanya penggunaan teknologi komputer dalam hal ini fintech. Maka digunakan tiga indikator untuk mengukur layanan fintech yaitu Perceived Usefulness, Perceived Ease of Use, dan Perceived of Risk.

Tiga komponen instrumen yang digunakan dalam penelitian ini untuk mengukur tingkat literasi keuangan ialah sesua pendapat Atkinson dan Messy (2012), OECD International Network on Financial Education yaitu Financial Knowledge, Financial Behaviour, dan Financial Attitude. Kemudahan yang diberikan fintech terhadap masyarakat mampu meningkatkan literasi keuangan (Sugiarti, 2019). Fintech has an important role in helping the financial literacy of Indonesian people including SMEs (Ragimun\&Yosepha, 2018). Pernyataan tersebut sesuai dengan hasil penelitian yang dilakukan oleh Aliyah (2019).

Oleh karena itu dirumuskan hipotesis sebagai berikut:

$\mathrm{H} 1$ : Layanan keuangan berbasis fintech berpengaruh positif terhadap literasi keuangan usaha menengah di Purwokerto.

\section{Fintech dan Inklusi Keuangan}

Fintech menawarkan "revolusi" atas penggabungan jasa keuangan dengan teknologi informasi yang telah meningkatkan kualitas layanan keuangan, dan menciptakan stabilitas keuangan. Fintech menunjuk pada pengunaan teknologi untuk memberikan solusi-solusi keuangan (Arner, et al., 2015). Secara spesifik, fintech didefinisikan sebagai aplikasi teknologi digital untuk masalah-masalah intermediasi keuangan (Aaron, et al., 2017). Sesuai dengan yang tercantum dalam OECD (2016) bahwa dalam penelitian ini digunakan 4 indikator untuk mengukur tingkat inklusi keuangan yaitu Product holding, Product awareness, Product choice, Seeking alternatives to formal financial services

Meilisa et al (2014) memaparkan bahwa inklusi keuangan merupakan suatu keadaan dimana mayoritas individu dapat memanfaatkan jasa keuangan yang tersedia serta meminimalisir adanya kelompok individu yang belum sadar akan manfaat akses keuangan melalui akses yang telah tersedia tanpa biaya yang tinggi. Adanya fintech telah menjembatani akses keuangan bagi masyarakat dalam hal ini UMKM untuk dapat mengakses jasa keuangan dengan mudah. Kehadiran sejumlah perusahaan fintech turut berkontribusi dalam pengembangan UMKM. Implementasi fintech dalam meningkatkan keuangan inklusif pada UMKM (Muzdalifa et al, (2018). Hal tersebut juga didukung oleh hasil penelitian Ozili (2018) yang menemukan hubungan positif antara fintech terhadap inklusi keuangan. 
Oleh karena itu dirumuskan hipotesis sebagai berikut:

$\mathrm{H} 2$ : Layanan keuangan berbasis fintech berpengaruh positif terhadap inklusi keuangan usaha menengah di Purwokerto

\section{METODE PENELITIAN}

Populasi dari penelitian ini adalah seluruh pelaku usaha menengah di Purwokerto. Metode pengumpulan data yaitu dengan menyebarkan kuisioner dengan skala 1-5. Hair, et al (2010) dalam bukunya memaparkan bahwa ukuran sampel minimum adalah 100. Oleh karena itu disarankan ukuran sampel adalah 5-10 kali parameter. Dalam penelitian ini total sampelnya adalah 108 (12 x 9) pelaku usaha menengah di Purwokerto sebab terdapat 10 indikator dan 2 koefisien jalur sehingga total estimated parameternya adalah 12 parameter. Pengambilan sampel dalam penelitian ini menggunakan sampel jenuh karena populasinya cukup kecil. Untuk menguji model empiris, maka digunakan Structural Equation Modeling (SEM). Alat analisis lain yang digunakan adalah AMOS 21.0, SPSS 16.0 dan Microsoft Excel 2010.

\section{HASIL DAN PEMBAHASAN}

Berdasarkan hasil pengujian yang telah dilakukan menggunakan AMOS 21.0, SPSS 16.0 dan Microsoft Excel 2007 maka diperoleh hasil sebagai berikut:

\section{Analisis dan Hasil Uji Kesesuaian Model}

Uji terhadap kesesuaian model menunjukkan bahwa sebuah model sesuai atau fit terhadap data yang digunakan dalam penelitian. Hal ini dapat dilihat dari kriteria yang ada yaitu Chi-Square, Probability, CMIN/DF, GFI, AGFI, TLI, CFI, dan RMSEA. Menurut Hair, et al (2010) uji kesesuaian model ini dapat diterima atau model dikategorikan fit apabila minimal 5 kriteria tersebut terpenuhi. Hasil uji kesesuaian model dapat dilihat pada tabel 3 berikut ini:

Tabel 1. Hasil Uji Kesesuaian Model (Goodness of Fit Test)

\begin{tabular}{llcc}
\hline Indeks Kesesuaian Model & Cut-off Value & Hasil Analisis Model & Keterangan \\
\hline$\chi^{2}-$ Chi Square & $<\chi^{2} 47,3999$ & 47,158 & Baik \\
Probability & $(\mathrm{p} 0,05 ; \mathrm{df} 33)$ & 0,052 & Baik \\
CMIN/DF & $>0,05$ & 1,429 & Baik \\
RMSEA & $<2,00$ & 0,063 & Baik \\
GFI & $<0,08$ & 0,925 & Baik \\
AGFI & $>0,90$ & 0,875 & Marginal \\
TLI & $>0,90$ & 0,921 & Marginal \\
CFI & $>0,95$ & 0,942 & Marginal \\
\hline
\end{tabular}

Sumber: Data Primer

Berdasarkan hasil statistik analisis SEM dalam uji kesesuaian model-goodness-of-fit test, diperoleh lima kriteria yang masuk dalam kategori baik dan tiga kriteria yang masuk dalam kategori marginal. Berdasarkan hasil tersebut, model dalam penelitian ini secara keseluruhan dapat dikategorikan sebagai a good model atau kategori model yang fit. 


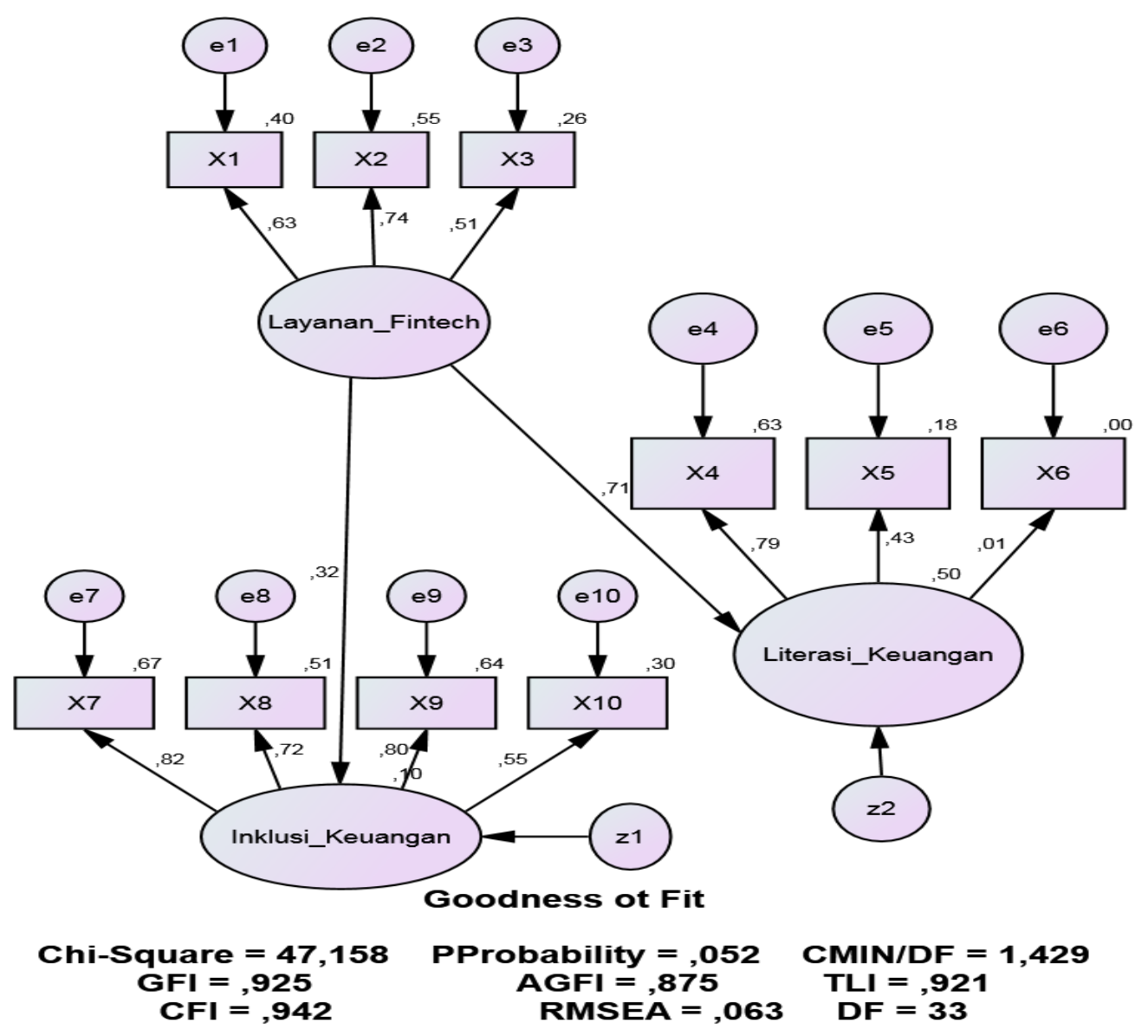

Gambar 2. Full Model

\section{Pengujian Hipotesis}

Pengujian hipotesis dilakukan dengan melihat nilai kritis atau $t_{\text {tabel, }}$ yaitu dengan cara membandingkan nilai $t_{\text {tabel }}$ tersebut dengan nilai $t_{\text {hitung }}$ dalam penelitian atau membandingkan nilai $p$ dengan 0,05 . Hipotesis dikatakan diterima apabila nilai $t_{\text {tabel }}<t_{\text {hitung }}$ atau $p<0,05$. Berdasarkan tabel distribusi $t$, besarnya nilai tabel dalam penelitian ini yaitu dengan jumlah sampel 110 dan tingkat signifikansi $5 \%(0,05)$ adalah sebesar 1.659 . Sedangkan untuk nilai thitung pada hubungan antar variabel penelitian ini dapat dilihat pada tabel 3 .

Tabel 3. Hasil Uji Hipotesis Penelitian

\begin{tabular}{|c|c|c|c|c|}
\hline Hipotesis & $\begin{array}{l}\text { Nilai } \\
\text { C.R. }\end{array}$ & $\begin{array}{l}\text { Nilai } \\
\mathrm{t}_{\text {table }}\end{array}$ & $P$ & Hasil Uji \\
\hline Layanan Keuangan Fintech $\rightarrow$ Literasi Keuangan & 3,886 & 2,035 & 0,000 & Diterima \\
\hline Layanan Keuangan Fintech $\rightarrow$ Inklusi Keuangan & 2,446 & 2,035 & 0,014 & Diterima \\
\hline
\end{tabular}

Sumber: Data Primer 
Pembahasan Hipotesis

Hubungan Layanan Keuangan Fintech dengan Literasi Keuangan

$\mathrm{H} 1$ : Layanan keuangan fintech berpengaruh positif terhadap literasi keuangan

Hipotesis yang menyatakan bahwa layanan keuangan fintech berpengaruh positif terhadap literasi keuangan, diterima. Diterimanya hipotesis ini menandakan bahwa terdapat pengaruh antara layanan keuangan fintech dengan literasi keuangan. Dengan demikian, semakin banyak UMKM pengguna fintech maka UMKM tersebut akan semakin tinggi tingkat literasi keuangannya. Hasil kuesioner menunjukkan bahwa fintech menawarkan kemudahan dan kepraktisan akses layanan keuangan. Hal tersebut yang menjadikan fintech sebagai layanan keuangan yang mampu mendorong peningkatan Iterasi keuangan. Hasil penelitian ini mendukung hasil penelitian sebelumya yang pernah dihasilkan oleh (Sugiarti, 2019), Ragimun\&Yosepha, (2018), Aliyah (2019) yang berpendapat bahwa fintech berpengaruh positif tehadap literasi keuangan.

\section{Hubungan Layanan Keuangan Fintech dengan Inklusi Keuangan}

$\mathrm{H} 2$ : Layanan keuangan fintech berpengaruh positif terhadap inklusi keuangan

Hipotesis yang menyatakan bahwa layanan keuangan fintech berpengaruh positif terhadap inklusi keuangan, diterima. Diterimanya hipotesis ini menunjukkan bahwa terdapat pengaruh positif antara layanan keuangan fintech dengan inklusi keuangan. Dengan demikian, fintech yang diterapkan oleh UMKM berpengaruh secara langsung dalam terciptanya peningkatan inklusi keuangan. Berdasarkan hasil kuesioner, UMKM merasa terbantu dengan adanya fintech menghilangkan keterbatasan akses informasi layanan keuangan karena segala sesuatunya bisa diakses secara online. Hasil penelitian ini sejalan dengan penelitian yang dilakukan oleh Muzdalifa et al, (2018), Ozili (2018). Mereka menyatakan bahwa pengaruh fintech yang positif memainkan peranan penting dalam meningkatkan inklusi keuangan.

\section{KESIMPULAN}

Hasil dari penelitian ini menunjukkan bahwa layanan keuangan berbasis fintech memiliki pengaruh positif terhadap literasi keuangan dan inklusi keuangan usaha menengah di Purwokerto. Selain itu, dalam penelitian ini juga dapat dibuktikan bahwa layanan keuangan berbasis fintech diperlukan masyarakat untuk memperluas wawasannya terkait literasi keuangan dan inklusi keuangan. Dari hasil penelitian ini diharapkan dapat membangun kesadaran pelaku usaha menengah bahwa munculnya fintech bukan merupakan ancaman tetapi justru akan semakin mempermudah dalam hal kepraktisan melakukan kredit, pembayaran tagihan maupun pengecekan pembayaran dengan cepat dan mudah. Hal tersebut sejalan dengan program Otoritas Jasa Keuangan (OJK) dalam upaya meningkatkan tingkat literasi keuangan dan inklusi keuangan. Dalam pelaksanaan penelitian ini, ada beberapa hal yang menjadi keterbatasan bagi peneliti seperti keterbatasan pada satu sektor yaitu hanya usaha menengah. Sebaiknya di penelitian mendatang bisa melakukan uji layanan keuangan berbasis fintech terhadap literasi keuangan dan inklusi keuangan pada mahasiwa, yang notabene mereka adalah generasi milenial yang identik dengan kepraktisan dan dipastikan sebagian besar adalah pengguna layanan fintech. Selain itu penelitian mendatang dapat mengkaji dengan lingkup area yang lebih luas lagi tidak hanya di Purwokerto.

\section{DAFTAR PUSTAKA}

Aaron, M., Rivadeneyra, F., dan Sohal, S. (2017). Fintech: Is this Time Different? A framework for Assessing Risks and Opportunities for Central Banks. Presented in Bank of Canada Staff Discussion Paper, Canada, Juli 10, 2017. 


\section{PERFORMANCE}

Jurnal Personalia, Financial, Operasional,

Marketing dam Sistem Informasi

Performance. Volume 27 Nomor 1 Tahun 2020, 12-20

Aliyah, Lia M \& Nurdin. (2019). Pengaruh Layanan Keuangan Berbasis Teknologi (Fintech) terhadap Literasi Keuangan Masyarakat Dago Atas, Bandung. Prosiding Manajemen, 5(1), 649-656. ISSN: 2460-6545.

Arner, D., J. Barberis, and R. Buckley. (2015). The Evolution of Fintech: A New Post-Crisis Paradigm?. UNSW Law Research Series, 047.

Atkinson A, Messy F. (2012). Measuring Financial Literacy: Results of The OECD/International Network on Financial Education (INFE) Pilot Study. Organization for Economic Cooperation and Development, 15.

Djawahir, A . (2018). Teknologi-Layanan Keuangan, Literasi-Inklusi Keuangan, dan Value pada Fintech Syariah di Indonesia. Second Proceedings Annual Conference for Muslim Scholars Teknologi-Layanan Keuangan. UNIRA Malang. 21-22 April .

Fiki Ariyanti. (2018, 19 Juli). Makin Menggurita, Ini Aturan Baru Pengawasan Fintech di Indonesia. Diakses dari https://www.cermati.com/artikel/makin-menggurita-ini-aturan-barupengawasan-fintech-di-indonesia.

Fitriani, Hanik. (2018). Kontribusi Fintech dalam Meningkatkan Keuangan Inklusif pada Pertanian. Jurnal Ekonomi IAIN Ponorogo, Vol 1 (1), 1-26.

Hair, Joseph.F.,et al. (2010). Multivariate Data Analysis. United States: Prentice Hall.

Https://www.ndrc.ie. Diakses 19 Agustus 2019.

Irmawati, Setyani., Damelia., Puspita. (2018). Model Inklusi Keuangan pada UMKM Berbasis Pedesaan. Journal of Economic and Policy. 6 (2), 103-213.

Meilisa Salim dan Yen Sun (2014). Analisis Implementasi Program Financial Inclusion Di Wilayah Jakarta Barat dan Jakarta Selatan (Studi pada Pedagang Golongan Mikro, Instansi Perbankan, Otoritas Jasa Keuangan dan Bank Indonesia), Jurnal Universitas Bina Nusantara. 4 (1), 123-143.

Muzdalifa, Irma., Rahma, Inayah A., Novalia, Bella D. (2018). Peran Fintech dalam Meningkatkan Keuangan Inklusif pada UMKM di Indonesia. Jurnal Ekonomi dan Perbankan Syariah. 3(1), $227-344$

Organization for Economics Co-operation and Development. (2016). Measuring Financial Literacy: Questionnaire and Guidance Notes for Conducting an Internationally Comparable Survey of Financial Literacy. Diakses 19 Agustus 2019, dari http://www.oecd.org/finance/financial-education/49319977.pdf.

Otoritas Jasa Keuangan. (2016). Survei Nasional Literasi dan Inklusi Keuangan 2016. Departemen Literasi dan Inklusi Keuangan Bidang Edukasi dan Perlindungan Konsumen. Jakarta: Otoritas Jasa Keuangan. Diakses dari https://sikapiuangmu.ojk.go.id...2016.pdf.

Ozili, Peterson K. (2018). Impact of Digital Finance on Financial Inclusion and Stability. Borsa Istanbul Review, 18 (4), 329-340. 
Performance. Volume 27 Nomor 1 Tahun 2020, 12-20

Ragimun \& Yosepha. (2018). The Role of Fintech Encourages the Export of Small Medium Enterprises in Indonesia. Journal of Social and Development Science, 9 (3), 66-77.

Romanova, I., \& Kudinska, M. (2016). Contemporary Issues in Finance: Banking and Fintech: A Challenge or Opportunity?. Contemporary Studies in Economic and Financial Analysis, 98, 21-35.

Setiawan, Kodrat. (2020, Februari 24). Jokowi Soroti Indeks Literasi dan Inklusi Keuangan RI yang Rendah. Bisnis Tempo Online. Diakses dari https://bisnis.tempo.co/read/1300621/jokowisoroti-indeks-literasi-dan-inklusi-keuangan-ri-yang-rendah.

Sugiarti, Evy N., Diana N., Mawardi. (2019). Peran Fintech Dalam Meningkatkan Literasi Keuangan pada Usaha Mikro Kecil Menengah Di Malang. E-JRA, 8 (4), 90-104. 